\title{
RESENHA: REPRESENTAÇÃO, DIALOGICIDADE E A LINGUAGEM COMO QUESTÕES CENTRAIS DA PSICOLOGIA SOCIAL: UMA TEORIA PSICOSSOCIAL DA MENTE
}

\author{
Denis Barros de Carvalho \\ Universidade Federal do Piauí, Teresina, Brasil
}

\section{Marková, I. (2006). Dialogicidade e representações sociais: as dinâmicas da mente. Petrópolis: Vozes}

Ivana Marková é uma cientista social praticamente desconhecida no Brasil, apesar de possuir uma contribuição relevante para a Teoria das Representações Sociais (Marková, 2000a, 2000b; Wagner et al., 1999), principalmente na discussão sobre o papel da linguagem e da dialogicidade para a Psicologia (Marková, 1997, 2003, 2006b).

Esse desconhecimento decorre da ausência de publicação de suas obras em nosso país. Uma amostra de sua competência aparece no livro Representações Sociais, de Serge Moscovici, publicado pela Editora Vozes em 2003. Três anos depois, a mesma editora veio a publicar o livro Dialogicidade e Representações Sociais: as Dinâmicas da Mente, livro que apareceu originalmente nos Estados Unidos em 2003.

O livro apresenta uma teoria do conhecimento social fundamentada nos conceitos de dialogicidade e representações sociais, desenvolvendo uma alternativa à teoria computacional da mente. Para a autora, a dialogicidade, entendida como a "capacidade da mente humana de conceber, criar e comunicar realidades sociais, é o fundamento da constituição da mente humana em termos do 'Alter"' (Marková, 2006a, p.15).

O conceito de dialogicidade ou dialogismo ${ }^{1}$ foi desenvolvido por autores como Rosenzweig $(1997,2001$, 2008), Buber (1979, 2007) e Bakhtin (1981, 2000), que considerou aspectos da comunicação, principalmente da interação eu/outro que eram desconsiderados pelos estudiosos de sua época.

O conceito de representações sociais, criado pelo psicólogo Serge Moscovici (2008), é originado no conceito de representações coletivas do sociólogo Émile Durkheim. De acordo com este autor,

o que as representações coletivas traduzem é o modo como o grupo se pensa em suas relações com os objetos que o afetam.... Para compreender a maneira como a sociedade representa a si mesma e o mundo que a cerca, é a natureza da sociedade, e não a dos particulares, que se deve considerar (Durkheim, 1999: XXIII).
Outros teóricos que influenciaram a construção do conceito de representações sociais foram Lévi-Bruhl, Piaget e Vigostky (Moscovici, 2003, pp. 182-194).

Moscovici propõe um conceito de representação social baseado no senso comum, no conhecimento e na comunicação. Para Marková, a teoria das representações sociais coloca a linguagem e a comunicação no centro da Psicologia Social.

A teoria do conhecimento social proposta por Marková possui ainda outra importante característica: é uma teoria que enfatiza a dinâmica e, portanto, a historicidade. Nas palavras da autora,

O conhecimento social é o conhecimento em comunicação e o conhecimento em ação. Não pode haver conhecimento social a menos que seja formado, mantido, difundido e transformado dentro da sociedade, entre indivíduos ou entre indivíduos e grupos, subgrupos e culturas. O conhecimento social se refere às dinâmicas da estabilidade e das mudanças (Marková, 2006a: 27).

O livro está dividido em sete capítulos e apresenta um índice onomástico de autores.

No primeiro capítulo, intitulado "Mudanças: um problema epistemológico para a Psicologia Social", a autora analisa os conceitos de estabilidade e das mudanças, argumentando que o pensamento e a linguagem são fenômenos dinâmicos, mas as teorias psicológicas se estruturam a partir de um modelo teórico fundado no conceito de estabilidade.

"Pensamento e antinomias", o segundo capítulo, apresenta uma visão histórica da ideia de antinomias em pensamento. Marková argumenta que a ideia de antinomia tem existido em vários períodos, desde a Grécia Antiga e a China até a Idade Média. Com o advento da ciência mecanicista do século XVII, o conceito praticamente desapareceu. No século XIX, as antinomias do pensamento emergiram na teoria hegeliana do conhecimento social.

O capítulo três (Lingüística e antinomias dialógicas) apresenta um estudo histórico sobre as antinomias na linguagem. No século XVII, aparece a primeira 
antinomia no estudo da linguagem e nas abordagens não-históricas versus históricas. No século XVIII, o movimento romântico apresenta outra antinomia: a natureza social versus a natureza individual da linguagem. Em Sussurre, já no século XX, aparece a dicotomia sincronia versus diacronia na abordagem dos estudos linguísticos. Finalmente, a filosofia do século XX trouxe a antinomia no diálogo, a antinomia entre Ego e Alter.

"Pensando pela boca", o capítulo quatro, desenvolve a ideia que as realidades sociais são criadas pela mente humana, através da relação dialógica entre o Ego e o Alter, relação essa também marcada pelo conflito, onde os envolvidos tentam mudar a perspectiva do outro e confirmar a sua, mediante um rico e multifacetado processo de comunicação. A esse processo denomina-se dialogicidade, de acordo com Marková.

No capítulo cinco, intitulado "Representações Sociais: velhas e novas", a autora apresenta as teorias de Durkheim e Moscovici e expõe as diferenças entre elas. A teoria das representações coletivas de Durkheim é construída no contexto de uma sociologia do conhecimento e tem as seguintes características: dualidade da natureza humana (sociedade e indivíduo), estabilidade, natureza institucional e confinada, o monologismo coletivo e a gênese contínua. A teoria das representações sociais de Moscovici, por sua vez, renovou a Psicologia Social, usando como principal recurso a dialogicidade e se caracteriza por: (a) a mudança em pensamento e a comunicação, (b) a polifasia em pensamento e (c) o pensamento de senso comum e o conhecimento.

Uma pergunta é o tema fundamental do capítulo seis: "como as epistemologias estáticas podem ser transformadas em dinâmicas?” (Marková, 2006a , p. 18). A autora, retomando algumas ideias de Karl Bühler e Serge Moscovici, demonstra a dinamicidade da relação triangular Ego-Alter-Objeto. Marková argumenta que há muitas características que fazem com que essas relações triangulares sejam dinâmicas: primeiro, a relação entre o Ego e o Alter é constituída de modo tenso. Segundo, a relação Ego-Alter-Objeto é simultânea e sequencial. Finalmente, a qualidade da relação entre o Ego-Alter-Objeto é definida por representações baseadas em crenças ou em conhecimentos. A autora exemplifica essa dinamicidade através de diálogos entre pessoas com dificuldades na fala e na comunicação e seus interlocutores, em processos de influência social e na criação e transformação das normas estéticas nas artes. Assim, "Tríade dialógica e processos de três componentes" se mostra um capítulo de grande densidade teórica (Marková, 2006a, p. 19).

O último capítulo, denominado "Entendendo themata e gerando representações sociais", discute o conceito de themata, considerado pela autora como o principal da teoria das representações sociais. De acordo com ela,

Os conteúdos estruturados das representações sociais são gerados a partir de antinomias culturalmente compartilhadas que se transformaram em problemas. É neste ponto que as condições sociais observam que estas antinomias interdependentes ficaram thematizadas e começaram a gerar representações sociais. Alguns exemplos de themata (thema no singular) ... são: comestível/não-comestível, liberdade/opressão e justiça/injustiça (Marková, 2006a, p. 19).

Marková (2006a) nos apresenta uma teoria do conhecimento social fundamentada na dialogicidade e nas representações sociais. Essa é a peculiaridade de sua contribuição para a Psicologia Social. Outro ponto importante é a sua contribuição para uma teoria alternativa da mente computacional.

Steven Pinker resume bem a teoria computacional da mente:

Ela afirma que crenças e desejos são informações, encarnadas como configurações de símbolos. Os símbolos são os estados físicos de bits de matéria, como os chips de um computador ou os neurônios do cérebro. Eles simbolizam coisas do mundo porque são desencadeados por essas coisas via órgãos dos sentidos e devido ao que fazem depois de ser desencadeados. Se os bits de matéria que constituem um símbolo são ajustados para topar com os bits de matéria que constituem outro símbolo exatamente de certo jeito, os símbolos correspondentes a uma crença podem originar novos símbolos correspondentes a outra crença relacionada logicamente com a primeira, o que pode originar símbolos correspondentes a outras crenças e assim por diante (Pinker, 2000, pp. 35-36).

Marková (2006a, pp. 34-38) aponta as seguintes limitações da teoria computacional da mente:

1. Os mecanismos físicos da mente são concebidos como "solipsismos auto-suficientes de comunicação", desconsiderando a condição de ser social do ser humano;

2. Apresentam explicações não-históricas da mente, reduzindo-a ao reino da causalidade e do determinismo;

3. A teoria computacional da mente tem uma linguagem corporal e inata que nada nos diz sobre a realidade, tornando a mente uma "máquina sintática" preocupada solipsisticamente com o "funcionamento interno de seus mecanismos cognitivos” (Marková, 2006a, p. 38).

A teoria da dialogicidade de Marková, em contraste, concebe a mente como um "fenômeno historicamente e culturalmente constituído em comunicação, tensão e mudança" (Marková, 2006a, p. 53). Essa teoria encontra uma antecipação nos trabalhos de Vigostky sobre o desenvolvimento psicológico da criança (Vigostky, 2000). 
Uma questão importante acerca do conceito de dialogicidade mencionado por Marková é a origem religiosa do "princípio dialógico" desenvolvido por autores como Martin Buber, Franz Rosenzweig e até mesmo Mikhail Bakhtin. A autora não desenvolve essa questão, lacuna essa que não revela aos seus leitores que é justamente na tradição judaica que se encontra uma alternativa à epistemologia monológica originada na tradição grega.

O Antigo Testamento define o rosto como o elemento mais importante do Ser Humano. O rosto aparece descrito sempre no plural (pānim) e é definido como o órgão que permite ao homem voltar-se para o outro através dos órgãos de comunicação (olhos, bocas e ouvidos). Para o Antigo Testamento, o ser humano não se reconhece através de um espelho, mas sim pela sua capacidade de responder a um chamado. Negar-se a escuta é como renunciar a vida. Escutar implica obrigatoriamente responder (Wolff, 2001).

O espaço não nos permite desenvolver esse tema, o que exigiria uma discussão acerca do desenvolvimento da Filosofia Judaica (Guttmann, 2003) e das diferenças da tradição vetero-testamental em relação à tradição grega (Auerbach, 2001).

Bakhtin era um homem profundamente religioso, e a relação entre sua fé e seu trabalho intelectual é resumida assim por Karerina Clark e Michael Holquist, eminentes estudiosos de sua obra:

Bakhtin não procurava Deus, no que São João da Cruz chamou de "a fuga do sozinho para o sozinho", mas no exato oposto, o espaço entre os homens transponível pela palavra, pela elocução. Em vez de buscar o lugar de Deus na estase e no silêncio, buscava-O na energia e na comunicação. Procurando uma conexão entre Deus e os homens, Bakhtin concentrou-se nas forças que possibilitavam as ligações, na sociedade e na linguagem, entre os homens (Clark \& Holquist, 1998, p. 87).

Apesar de não estudar a fundo a principal fonte da dialogicidade, a tradição judaica, Marková (2006a) nos brinda com um excelente livro sobre o assunto.

Esta tradução do livro de Ivana Marková faz parte da coleção Psicologia Social da Editora Vozes, coordenada por Pedrinho Guareschi e Sandra Jovchelovitch. Esta coleção, além de publicar textos dos mais importantes psicólogos sociais brasileiros, apresentou para o grande público brasileiro importantes textos da psicologia social europeia produzidos por autores como Serge Moscovici, Denise Jodelet, Michael Billig e a própria Ivana Marková.

\section{Nota}

${ }^{1}$ Os conceitos de dialogicidade e de dialogismo são usados como termos cambiáveis, embora às vezes algumas distinções sejam feitas entre eles. Bakthin usa o termo "dialogismo" para descrever sua proposta de Epistemologia das Ciências Huma- nas. A Epistemologia Dialógica de Marková (2006a, 2006b) desenvolve uma distinção entre Ciências Humanas e Naturais afirmando que estas são monológicas por lidarem com objetos reificados e sem voz, enquanto as Ciências Humanas (e as Sociais) são dialógicas porque lidam com a mente e a linguagem humanas multifacetadas e polifônicas, que são reflexivas, históricas, sociais e culturalmente vinculadas (Liu, 2004).

\section{Referências bibliográficas}

Auerbach, E. (2001). A cicatriz de Ulisses. In E. Auerbach, Mimesis (pp. 1-20). São Paulo: Perspectiva.

Bakhtin, M. (1981). Problemas da poética de Dostoiévski. São Paulo: Forense.

Bakhtin, M. (2000). Observações sobre a epistemologia das ciências humanas. In M. Bakhtin, Estética da criação verbal (pp. 399-414). São Paulo: Martins Fontes.

Buber, M. (1979). Eu e Tu. Campinas: Moraes.

Buber, M. (2007). Do diálogo e do dialógico. São Paulo: Perspectiva.

Clark, K. \& Holquist, M. (1998). Mikhail Bakhtin. São Paulo: Perspectiva.

Durkheim, E. (1999). As regras do método sociológico. São Paulo: Martins Fontes.

Guttmann, J. (2003). A filosofia do judaísmo: a histórica da filosofia judaica desde os tempos bíblicos até Franz Rosenzweig. São Paulo: Perspectiva.

Liu, L. (2004). Sensiting concept, themata and shareness: A dialogical perspective of social representations. Journal for the Theory of Social Behavior, 34(3), 249-264.

Marková, I. (1997). Language and authenticity. Journal for the Theory of Social Behavior. 27 (2-3), 265-275.

Marková, I. (2000a). The individual and society in psychological theory. Theory \& Psychology, 10(1), 107-116.

Marková, I. (2000b). Amédée or how to get rid of it: Social representations from a dialogical perspective. Culture \& Psychology, 6(4), 419-460.

Marková, I. (2003). Constitutions of the self: Intersubjectivity and dialogicality. Culture \& Psychology, 9(3), 249-259.

Marková, I. (2006a). Dialogicidade e representações sociais: as dinâmicas da mente. Petrópolis, RJ: Vozes.

Marková, I. (2006b). On 'the inner Alter' in dialogue. International Journal for Dialogical Science, 1(1), 125-147.

Moscovici, S. (2003). Representações sociais: investigações em psicologia social. Petrópolis, RJ: Vozes.

Moscovici, S. (2008). Psychoanalysis: Its image and its public. Cambridge: Polity.

Pinker, S. (2000). Como a mente funciona. São Paulo: Companhia das Letras.

Rosenzweig, F. (1997). La estrella de la Redención. Salamanca: Sigueme.

Rosenzweig, F. (2001). Foi et Savoir. Paris: Paris: Librairie philosophique J. Vrin.

Rosenzweig, F. (2008). Hegel e o Estado. São Paulo: Perspectiva.

Vigotsky, L. (2000). A formação social da mente. São Paulo: Martins Fontes.

Wagner, W., Farr, R., Jovchelovitch, S., Lorenzi-Cioldi, F., Marková, I., Duveen, G. \& Rose, D. (1999). Theory and method of Social Representations. Asian Journal of Social Psychology, 2(1), 95-125.

Wolff, H. (2001). Antropología del Antiguo Testamento. Salamanca: Sigueme. 
Denis Barros de Carvalho possui graduação em Psicologia pela Universidade Federal do Rio Grande do Norte (1995). Concluiu o mestrado (2001) e doutorado em

Psicologia Social (2007) na mesma instituição. Atualmente é professor Adjunto da Universidade Federal do Piauí e atua principalmente nos seguintes temas: formação do psicólogo, atuação profissional do psicólogo, políticas públicas, proteção à criança e ao adolescente, identidade profissional, Psicologia Social da Saúde e Psicologia Ambiental. Endereço para correspondência: Rua trevos 1125, Morada do Sol. Teresina/Piauí. CEP 64056210.

E-mail: denispsi@bol.com.br

Representação, dialogicidade e a linguagem como questões centrais da Psicologia Social: uma teoria psicossocial da mente Denis Barros de Carvalho

Recebido: 04/04/2008

$1^{\text {a }}$. Revisão: 19/11/2008

Aceite final: 20/11/2008 